University of Wollongong

Research Online

Faculty of Engineering and Information

Faculty of Engineering and Information

Sciences - Papers: Part B

Sciences

2019

Characterization of tantalum and tantalum nitride films on Ti6Al4V substrate prepared by filtered cathodic vacuum arc deposition for biomedical applications

Ay Ching Hee

University of Wollongong, ach897@uowmail.edu.au

Yue Zhao

University of Wollongong, Tianjin University of Technology, yue@uow.edu.au

Sina S. Jamali

University of Wollongong, sjamali@uow.edu.au

Avi Bendavid

CSIRO,Avi.Bendavid@csiro.au

Phil J. Martin

CSIRO, Phil.Martin@csiro.au

See next page for additional authors

Follow this and additional works at: https://ro.uow.edu.au/eispapers1

Part of the Engineering Commons, and the Science and Technology Studies Commons

Research Online is the open access institutional repository for the University of Wollongong. For further information contact the UOW Library: research-pubs@uow.edu.au 


\title{
Characterization of tantalum and tantalum nitride films on Ti6Al4V substrate prepared by filtered cathodic vacuum arc deposition for biomedical applications
}

\author{
Abstract \\ This paper explores tantalum and tantalum nitride thin films produced by filtered cathodic vacuum arc \\ deposition method as bio-stable surface treatment for Ti6Al4V titanium alloy. Effect of nitrogen to argon \\ gas ratio on microstructure of the deposited film has been investigated. Corrosion behaviour of the films \\ in simulated biological fluid solution was evaluated by electrochemical impedance spectroscopy. It was \\ found that both the Ta and Ta-N films enhanced corrosion resistance of the Ti6Al4V substrate with the \\ best protective characteristics achieved by the Ta- $\mathrm{N}$ film deposited at $0.25 \mathrm{~N} 2$ /Ar gas ratio. The \\ protective characteristic was attributed to the formation of tantalum oxide and oxynitride compound at \\ the surface, as verified by X-ray photoelectron spectroscopy. Increasing N 2 /Ar gas ratio increased \\ susceptibility to localized corrosion. The corrosion resistance decreased as the thickness of the film \\ increased to $1 \mu \mathrm{m}$.

\section{Disciplines} \\ Engineering | Science and Technology Studies

\section{Publication Details} \\ Hee, A., Zhao, Y., Jamali, S. S., Bendavid, A., Martin, P. J. \& Guo, H. (2019). Characterization of tantalum \\ and tantalum nitride films on Ti6Al4V substrate prepared by filtered cathodic vacuum arc deposition for \\ biomedical applications. Surface and Coatings Technology, 365 24-32.
}

\section{Authors}

Ay Ching Hee, Yue Zhao, Sina S. Jamali, Avi Bendavid, Phil J. Martin, and Hongbo Guo 


\title{
Abstract ID: 97 \\ Characterization of tantalum and tantalum nitride films on Ti6Al4V substrate prepared by \\ filtered cathodic vacuum arc deposition for biomedical applications
}

$\underset{\mathrm{d}}{\text { Ay Ching Hee }}{ }^{\mathrm{a}}$, Yue Zhao ${ }^{\text {a,b, }}{ }^{*}$, Sina S. Jamali ${ }^{\mathrm{a}}$, Avi Bendavid ${ }^{\mathrm{c}}$, Philip J. Martin ${ }^{\mathrm{c}}$, Hongbo Guo

${ }^{a}$ School of Mechanical, Materials, Mechatronic and Biomedical Engineering, University of Wollongong, NSW 2522, Australia.

${ }^{\mathrm{b}}$ School of Materials Science and Engineering, Tianjin University of Technology, Tianjin 300384, China.

${ }^{\mathrm{c}}$ CSIRO, Manufacturing Business Unit, PO Box 218, Lindfield, NSW 2070, Australia.

${ }^{\mathrm{d}}$ School of Materials Science and Engineering, Beihang University, Beijing 100191, China.

* Corresponding author: yue@uow.edu.au

Telephone no: +61242215549 , Fax: +61242215474

\begin{abstract}
This paper explores tantalum and tantalum nitride thin films produced by filtered cathodic vacuum arc deposition method as bio-stable surface treatment for Ti6Al4V titanium alloy. Effect of nitrogen to argon gas ratio on microstructure of the deposited film has been investigated. Corrosion behaviour of the films in simulated biological fluid solution was evaluated by electrochemical impedance spectroscopy. It was found that both the Ta and Ta-N films enhanced corrosion resistance of the Ti6Al4V substrate with the best protective characteristics achieved by the Ta- $\mathrm{N}$ film deposited at $0.25 \mathrm{~N}_{2} / \mathrm{Ar}$ gas ratio. The protective characteristic was attributed to the formation of tantalum oxide and oxynitride compound at the surface, as verified by X-ray photoelectron spectroscopy. Increasing $\mathrm{N}_{2} / \mathrm{Ar}$ gas ratio increased susceptibility to localized corrosion. The corrosion resistance decreased as the thickness of the film increased to $1 \mu \mathrm{m}$.
\end{abstract}




\section{Keywords:}

Tantalum films; tantalum nitrides; X-ray photoelectron spectroscopy; electrochemical impedance spectroscopy

\section{Introduction}

Prosthetic implants made of titanium alloys are widely used because of their high strength-toweight ratio and superior biocompatibility [1]. The thin oxide surface layer $(1.5-10 \mathrm{~nm})$ that forms naturally on the titanium metal exposed to air at room temperature improves the stability of the surface [2]. Unfortunately, titanium implants have poor wear resistance and the generated wear debris accelerates the rate of electrochemical reactions between the surface of the implant and the surrounding physiological environment [3]. Therefore, further development is needed to extend the longevity of these implants and decrease the risk of an agonizing repeat implantation procedure. Over the past few decades transition metal nitride and oxide films have been utilized to improve the corrosion and mechanical properties of biomedical components due to their excellent resistance to wear resistance and corrosion [4-6]. The metal nitride and oxide coatings have a strong covalent bonding which leads to high hardness and chemical stability, attributes which and make them suitable candidates for bioactive coatings. Several studies have shown that Ta-N films can promote cell proliferation [7,8], enhance corrosion resistance [9], has good blood compatibility and they are suitable for fabricating artificial heart valves [10]. Tantalum oxide and oxynitride $(\mathrm{TaON})$ have a better corrosion resistance than the native oxide film on uncoated Ti6Al4V $[11,12]$. The stability of the TaON coating is attributed to the release of ammonia $\left(\mathrm{NH}_{4}{ }^{+}\right)$or nitrate ions which consumes protons and increases the overall $\mathrm{pH}$ [13]. Possible acidification caused by dissolution of metal is then neutralized by the ammonia. The $\mathrm{NH}_{4}{ }^{+}$ions 
undergo further reaction to form stable compounds of nitrate and nitrites, which act as either corrosion inhibitors or stabilize the passive films and improve resistance to pitting corrosion $[12,14]$.

Despite the promising chemical and mechanical properties of metal nitrides, investigations into the tantalum nitrides prepared by filtered cathodic vacuum arc deposition (FCVAD) are limited. Tantalum films enhanced the mechanical and corrosion properties of the titanium alloys substrate, have been reported in our previous studies [15-17]. The corrosion resistance decreased with increasing nitrogen level in the sputtered Ta-N films, as reported by Mendizabal et al. [18]. The cathodic-arc Ta-N thin films improved the corrosion resistance of AISI 317L stainless steel substrate [19]. In this study, we evaluate the performance of the Ta and Ta-N films deposited on Ti6A14V substrate for biomedical applications. The $\mathrm{N}_{2} / \mathrm{Ar}$ gas ratio during film deposition was varied to study its effect on the structure and electrochemical properties of the films. In order to simulate and examine the performance of the coating in the human body and understand the reaction mechanisms, Ta and Ta-N films was tested in simulated biological fluid using electrochemical impedance spectroscopy (EIS). The surface chemistry of the samples before and after corrosion tests was then examined using X-ray photoelectron spectroscopy for a better understanding of the corrosion protection mechanism.

\section{Experimental procedures}

\subsection{Deposition conditions}


Ti6Al4V sheet substrates of $20 \times 20 \times 2 \mathrm{~mm}^{3}$ were ground and polished using $15 \mu \mathrm{m}$ diamond polycrystalline suspension and then polished with an oxide polishing suspension consisting of 2 $\mathrm{ml}$ ammonia and $1 \mathrm{ml}$ hydrogen peroxide. The deposition was carried out using an in-house built filtered cathodic vacuum arc deposition and the deposition parameters are summarized in Table 1. The arc cathode (the target) was made of high purity tantalum (purity, $99.99 \%$ ) with a diameter of $58 \mathrm{~mm}$. The chamber in the deposition system reached a base pressure of $1.0 \times 10^{-2} \mathrm{~Pa}$ prior to deposition. The DC arc current and substrate voltage bias were set to $200 \mathrm{~A}$ and $-100 \mathrm{~V}$, respectively for all the samples. The $\mathrm{N}_{2} / \mathrm{Ar}$ gas ratio was varied from $0-0.75$, and is defined as the ratio of the mass flow rate of nitrogen to the total mass flow rate of argon and nitrogen. Gas pressure during deposition was between $0.35-0.40 \mathrm{~Pa}$, as measured with a MKS capacitor gauge. To investigate the influence of film thickness on the electrochemical performance, two samples with $\mathrm{N}_{2} / \mathrm{Ar}$ gas ratio of 0 and 0.50 were prepared using a longer deposition time of $30 \mathrm{~min}$. The thickness of the 5 minutes deposited films was found to vary in the range of $233-365 \mathrm{~nm}$. The thickness of the films with a deposition time of 30 minutes at 0 and $0.50 \mathrm{~N}_{2} / \mathrm{Ar}$ gas ratio were 0.7 $\mu \mathrm{m}$ and $1 \mu \mathrm{m}$, respectively.

\subsection{Surface analysis}

Grazing-incidence X-ray diffraction (XRD) tests of the deposited films were carried out with a GBC MMA diffractometer equipped with $\mathrm{Cu} \mathrm{K \alpha}$ incident radiation. The XRD scan was in the 2 theta mode at a glancing angle of $5^{\circ}$ from $30^{\circ}$ to $80^{\circ}$ in $0.02^{\circ}$ steps. Surface topography and roughness of the films were examined using a Veeco Dimension ${ }^{\mathrm{TM}} 3100$ atomic force microscope (AFM) operating in contact mode over a scanning area of $2 \times 2 \mu \mathrm{m}^{2}$ with a scanning 
rate of $1 \mathrm{~Hz}$. The contact angle of the surface was measured by the sessile drop method in a contact angle goniometer (Rame-Hart Instrument). $2 \mu \mathrm{l}$ of the testing liquid, i.e. deionized water and fetal bovine serum (FBS) respectively, was used to measure the contact angle on the surface, these measures were repeated five times and an average value is reported. The thickness of the films was measured from the cross-section transmission electron microscope (TEM) specimens prepared using focused ion beam (FIB) technique on an FEI xT Nova Nanolab 200 work station.

\subsection{Electrochemical measurements}

Measurements of electrochemical impedance spectroscopy (EIS) were taken with a Gamry Reference 600 potentiostat (Gamry Instruments, Warminster, PA, USA). A conventional threeelectrode electrochemical cell was used with platinum and $\mathrm{Ag} / \mathrm{AgCl}$ as auxiliary and reference electrodes, respectively. The working electrode surface area of $0.8 \mathrm{~cm}^{2}$ was exposed to the test electrolyte via a glass cell affixed to the surface by an O-ring and clamp. A simulated biological fluid (SBF) solution was used as the test solution because its ionic composition is similar to human blood plasma. The SBF was prepared by dissolving analytical grade mixtures of $\mathrm{NaCl}$, $\mathrm{NaHCO}_{3}, \mathrm{Na}_{2} \mathrm{CO}_{3}, \mathrm{KCl}, \mathrm{K}_{2} \mathrm{HPO}_{4} \cdot 3 \mathrm{H}_{2} \mathrm{O}, \mathrm{MgCl}_{2} \cdot 6 \mathrm{H}_{2} \mathrm{O}, \mathrm{CaCl}_{2}$, and $\mathrm{Na}_{2} \mathrm{SO}_{4}$ in distilled water. The HEPES (4-(2-Hydroxyethyl) piperazine-1-ethanesulfonic acid) was dissolved in $0.2 \mathrm{M} \mathrm{NaOH}$ solution in a separate volumetric flask before adding it into the mixture. The $\mathrm{pH}$ of SBF solution was $7.4 \pm 0.5$. The electrochemical cell was placed in a Faraday cage in order to minimize interference from other electromagnetic devices. The sample was exposed to the electrolyte for $60 \mathrm{~min}$ at $37^{\circ} \mathrm{C}$ prior to the electrochemical testing in order to establish the steady-state potential. Impedance measurements were conducted in the frequency range of $0.01 \mathrm{~Hz}-10 \mathrm{kHz}$ with a data 
density of 10 points per decade at their respective open circuit potentials. The measurements were carried out by applying sinusoidal wave perturbations of $10 \mathrm{mV}$ RMS in amplitude. The samples were then analyzed by the JEOL JSM-6490 SEM. X-ray photoelectron spectroscopy spectrometer (XPS) was performed using a Specs SAGE 150 XPS operated with Mg K $\alpha$ X-ray source at $10 \mathrm{keV}$ and $10 \mathrm{~mA}$. The data were calibrated to the adventitious $\mathrm{C} 1 \mathrm{~s}$ peak present at $284.8 \mathrm{eV}$ to minimize sample charging.

\section{Results and discussion}

\subsection{Film structure and surface topography}

Fig. 1 shows the XRD patterns of uncoated Ti6Al4V substrate, Ta and Ta-N films prepared at various $\mathrm{N}_{2} / \mathrm{Ar}$ gas ratios. The XRD pattern of uncoated Ti6A14V substrate agrees with the characteristics peaks of Ti6A14V substrate reported in the literature [20-22]. The Ta and Ta-N films exhibit peak broadening from $33^{\circ}$ to $38^{\circ}$, indicating a significant amount of amorphous phase in the film deposited. Some peaks from the substrates are observed in the spectra of the film samples due to the thin film thickness. At pure Ar gas pressure the film has a tetragonal $\beta$ Ta structure (JCPDS-25-1280), but as the $\mathrm{N}_{2} /$ Ar gas ratio increased to $0.25,0.50$ and 0.75 , minor peaks which correspond to hexagonal Ta-N (JCPDS-39-1485) appeared, as did tetragonal $\beta-\mathrm{Ta}$. The result is consistent with the work reported by Kim and Cha [23], except that orthorhombic $\mathrm{Ta}_{3} \mathrm{~N}_{5}$ was not found in this work. The structure of tantalum nitrides is formed by the closely packed Ta atoms with $\mathrm{N}$ atoms inserted in interstitial sites [24]. A wide range of nitrogen-rich compounds ( $\mathrm{Ta}_{5} \mathrm{~N}_{6}, \mathrm{Ta}_{4} \mathrm{~N}_{5}, \mathrm{Ta}_{3} \mathrm{~N}_{5}$ ) may form as the amount of nitrogen increases. The 
complexity of the Ta-N compounds is well reported in Ref. [25]. The equilibrium and metastable phases formed depend on the deposition procedures and conditions.

Fig. 2 presents the AFM deflection images of the Ta-N films at different nitrogen to argon gas ratios, with a Z-range of $30 \mathrm{mV}$. Pure Ta film $\left(0 \mathrm{~N}_{2} / \mathrm{Ar}\right.$ gas ratio $)$ has a very smooth surface with an average roughness of $3 \mathrm{~nm}$. The smooth surface of the pure Ta film is attributed to the growth of an amorphous film, which is in accordance with the XRD result. As the $\mathrm{N}_{2} / \mathrm{Ar}$ gas ratio increases the surface topography shows island style growth of about $100 \mathrm{~nm}$ (Fig. 2 (b)). The surface of the film with a $0.50 \mathrm{~N}_{2} / \mathrm{Ar}$ gas ratio, as shown in Fig. 2 (c) tends to disintegrate between the colonies of the islands and makes the surface rougher, a result attributable to the reduced surface mobility of the atoms added by the formation of Ta-N bonding during deposition. The average surface roughness of the TaN film is $25 \mathrm{~nm}$ and $17 \mathrm{~nm}$ for 0.25 and $0.50 \mathrm{~N}_{2} / \mathrm{Ar}$ gas ratios, respectively. The surface becomes smoother $\left(\mathrm{R}_{\mathrm{a}}=10 \mathrm{~nm}\right)$ in the Ta-N film of $0.75 \mathrm{~N}_{2} / \mathrm{Ar}$ gas ratio, probably due to the prolonged time for the migration of surface atoms due to a very low growth rate.

\subsection{Wettability test of the Ta and Ta- $N$ film surfaces}

Surface wettability and surface biocompatibility are important parameters which influence cell growth. The average contact angle of water and FBS is reported in Table 2. The contact angles of water and bovine serum of the Ta-N coated samples are higher than the contact angle of the uncoated sample. However, the sample deposited at pure Ar gas pressure ( $0 \mathrm{~N}_{2} / \mathrm{Ar}$ gas ratio) has a high water contact angle and a low contact angle when the sample was exposed to the FBS. 
This means that while the pure Ta surface presents hydrophobicity, it does not restrain the affinity between FBS and the film surface as much. The Ta-N films $\left(\mathrm{N}_{2} / \mathrm{Ar}\right.$ gas ratio of 0.25 , 0.50 and 0.75 ) has similar contact angles for both water and FBS from $81^{\circ}-88^{\circ}$, indicating little change in the contact angle in relation to the presence of Ta-N phase in the films. Literature suggests that cell proliferation increases with increasing surface wettability [26,27]. Here, a contact angle less than $90^{\circ}$ for Ta and Ta-N films indicates a less hydrophobic surface that is expected to promote cell adhesion and proliferation.

\subsection{Electrochemical measurements}

Fig. 3 shows the impedance spectra of the Ta-N films produced at different $\mathrm{N}_{2} / \mathrm{Ar}$ gas ratios after exposure to SBF for 1 hour. The Nyquist plot, Fig. 3 (a), shows a relatively larger semi-circle for the coated samples at 0 and $0.25 \mathrm{~N}_{2} / \mathrm{Ar}$ gas ratios, which indicates an increased resistance of the surface layer with the most capacitive behavior for the sample prepared at $0.25 \mathrm{~N}_{2} / \mathrm{Ar}$ gas ratio. Fig. 3 (b) shows a magnified section of the Nyquist plot in the lower range of values in Fig. 3 (a). In Fig. 3 (b) and Fig. 3 (d), it is evident that the Ta and Ta-N coated samples have much higher impedances than the uncoated Ti6Al4V substrate, which implies that the passive film formed on the coated surfaces is more protective than for the uncoated Ti6A14V in SBF. Fig. 3 (b) and Fig. 3 (d) also suggest that there is a threshold for $\mathrm{N}_{2} / \mathrm{Ar}$ gas ratio after which the impedance begins to decrease. Low-frequency $(<1 \mathrm{~Hz})$ impedance is lower in the thick $30 \mathrm{~min}$ Ta film with $0 \mathrm{~N}_{2} / \mathrm{Ar}$ gas ratio, whereas the thick 30 min Ta film with $0.50 \mathrm{~N}_{2} / \mathrm{Ar}$ gas ratio has a higher impedance than the thinner 5 minute film. The mid-frequency region of the Bode plots can be used to characterize local surface defects, while the reactions on the surface, e.g. charge transfer, are 
indicated by the low-frequency region $(<1 \mathrm{~Hz})$ [28]. As Fig. 3 (c) shows, a significant change in the phase angle in the low-frequency region for the samples of $0.50 \mathrm{~N}_{2} / \mathrm{Ar}$ gas ratio $+5 \mathrm{~min}$ and $0.75 \mathrm{~N}_{2} / \mathrm{Ar}$ gas ratio $+5 \mathrm{~min}$, showing that surface was acting like a non-ideal or leaking capacitor. This is possibly due to the passive film of the sample becoming unstable and defective after immersion in SBF, causing a large variation in the phase angle. While the phase shift reached $85^{\circ}$ for the sample of $0.25 \mathrm{~N}_{2} / \mathrm{Ar}$ gas ratio $+5 \mathrm{~min}$, implying a passive film present on the surface with highly capacitive response. Ti6A14V substrate has the lowest phase shift in the low-frequency range of the Bode plot, as shown in Fig. 3 (d). However, the passivating layer on top of the Ta-N films acts like an insulating layer that offers corrosion protection in a buffered biological environment. Similar protective properties of Ta-N films on $316 \mathrm{~L}$ stainless steel attributable to the formation of a protective surface layer, was reported by Alishahi et al [29].

Table 3 presents a quantitative analysis of EIS data by fitting the appropriate electrical equivalent circuit (EEC). The EEC model with two loop elements, as shown in Fig. 4 (a) produced a good fit on the impedance data for Ti6Al4V substrate and Ta-N coated samples except for the film with $0.25 \mathrm{~N}_{2} / \mathrm{Ar}$ gas ratio $+5 \mathrm{~min}$. The impedance data for the sample of $0.25 \mathrm{~N}_{2} / \mathrm{Ar}$ gas ratio $+5 \mathrm{~min}$ fit best with the EEC model with one time constant (loop element), as shown in Fig. 4 (b). In the circuit, $R_{s}$ represents the resistance of the solution between the working and reference electrodes, $Q_{\text {oxide film }}$ and $R_{\text {oxide film }}$ are constant phase element (CPE) and resistance associated with the oxide film on the surface. The constant phase element (CPE) is indicative of the capacitive contribution and its deviation from ideal dielectric behaviour due to surface heterogeneities such as roughness, inhomogeneous surface, absorption of ions or possible variations in the physical properties of the covering film [30]. The exponent $n$ indicates a 
variation from ideal capacitor/resistor where $n=1$ for the pure capacitor, and $n=0$ for the pure resistor. $Q_{d l}$ and $R_{c t}$ are the CPE and resistance associated with the electrical double layer and charge transfer resistance, respectively. The simulation model with one time constant for the 0.25 $\mathrm{N}_{2} / \mathrm{Ar}$ gas ratio $+5 \mathrm{~min}$ indicates the formation of a uniform oxide layer without defects. The 0.25 $\mathrm{N}_{2} / \mathrm{Ar}$ gas ratio $+5 \mathrm{~min}$ has the highest charge transfer resistance of $3607 \mathrm{k} \Omega \mathrm{cm}^{2}$ of the tested samples. This result indicates that the surface itself affords the best corrosion protection due to the stability of passive film.

Fig. 5 shows the SEM images of the specimens after one hour immersion in SBF and then 20 minutes of EIS testing. A layer of corrosion product was clearly visible on the pure Ta film after EIS testing, as shown in Fig. 5 (a). An EDS analysis of the corroded surface shown in Fig. 6 confirmed the presence of oxygen, tantalum, titanium, aluminium, vanadium, chlorine, sodium, calcium and potassium; the calcium, sodium, chlorine and potassium came from the SBF. Fig 5 (b), Fig 5 (c) and Fig. 5 (d) show the SEM images of Ta-N films at $0.25 \mathrm{~N}_{2} / \mathrm{Ar}$ gas ratio $+5 \mathrm{~min}$, $0.50 \mathrm{~N}_{2} / \mathrm{Ar}$ gas ratio $+5 \mathrm{~min}$ and $0.75 \mathrm{~N}_{2} / \mathrm{Ar}$ gas ratio $+5 \mathrm{~min}$, respectively. Under the same magnification, the formation of small pits was more obvious as the $\mathrm{N}_{2} / \mathrm{Ar}$ gas ratio increased. Fig. 7 (a) demonstrates the corroded surface at other regions of the $0.50 \mathrm{~N}_{2} /$ Ar gas ratio $+5 \mathrm{~min}$ Ta-N. It is apparent that the Ta-N film is susceptible to pitting corrosion, where the corrosive liquid diffuses into the coating and leads to corrosion pits, as shown in the Fig. 7 (b) at a magnification of $\times 1000$. Ta-N films with more nitrogen and high volume fraction of TaN is expected to result in sharper change in Young's modulus and hardness across the film/substrate interface, and hence poor film adhesion and coating delamination. The multiple phase combination of Ta, TaN and some sub stoichiometric compounds in the $0.25 \mathrm{~N}_{2}$ /Ar gas ratio sample may also benefit the 
toughness and resistance to crack propagation inside the film [4, 18]. Fig. 5 shows coating delamination and more pits with large exposed areas for TaN films with 0.5 and $0.75 \mathrm{~N}_{2} / \mathrm{Ar}$ gas ratios. The TaN film with $0.25 \mathrm{~N}_{2} / \mathrm{Ar}$ gas ratio exhibits less defects and therefore its corrosion resistance is better than other samples with higher nitrogen level. With the Ta-N films at a deposition time of 30 minutes, i.e. Fig. 5 (e) and Fig. 5 (f), film detachment was clearly evident. The corroded surface of the thicker film is prone to formation of micro cracks. There is the possibility of a more distinct difference in reactivity between the grain boundaries and the rest of surface in the thicker film compared to that of the thinner film. As reported by Wei et al. [31], the larger stresses in a thicker coating create more local defects such as micro-fractures. Those defects allow more eroding ions to enter into the coating and worsen the corrosion resistance of the oxide coating. Similarly, the thicker Ta-N films in this study exhibit coating defects which expedited the formation of micro cracks after immersion in SBF.

The corrosion seen in Fig. 5 (a) and Fig. 5 (e) and the EDS analysis in Fig. 6 confirms the formation of a surface layer of calcium phosphate. The pure Ta film exhibits a somewhat protective effect because the pores are sealed by the precipitation of calcium phosphate in the electrolyte. Hydrated oxide film (Ta-OH group) was formed by a slow hydration of tantalum oxide layer in the SBF solution. This Ta hydroxide reacts with calcium ion and phosphate ion on the metal surface and build up a layer of calcium phosphate [32,33]. Similar results were reported by Valero Vidal and Igual Munoz [34], on the protective effect that phosphate had on the stainless steel in phosphate buffered saline solution that improves the passive behaviour by increasing the charge transfer resistance. In Ta-N coated Ti6Al4V substrate, passive film forms and protects the substrate from degradation and generates a capacitive response. 


\subsection{X-ray photoelectron spectroscopy analysis}

Fig. 8 compares the Ta $4 \mathrm{f}$ core-level XPS spectra of pure Ta film before and after corrosion tests. The deconvolution of all four Ta $4 \mathrm{f}$ spectra was conducted with a constraining condition where all the $4 f_{7 / 2}-4 f_{5 / 2}$ doublets are of a fixed area ratio of $4: 3$ and an energy separation of $1.91 \mathrm{eV}$ [35,36]. As shown in Fig. 8 (a), Ta $4 \mathrm{f}$ spectrum is de-convoluted to four doublets consisting of $\mathrm{Ta}_{2} \mathrm{O}_{5}$, Ta sub-oxides with lower oxidation states $\left(\mathrm{TaO}_{2}\right.$ and $\left.\mathrm{TaO}\right)$ and metallic $\mathrm{Ta}^{0}$. The $\mathrm{Ta} 4 \mathrm{f}_{7 / 2}$ and $\mathrm{Ta} 4 \mathrm{f}_{5 / 2}$ peaks located at $26.3 \mathrm{eV}$ and $28.2 \mathrm{eV}$ are attributed to the most stable form of pentavalent state, $\mathrm{Ta}_{2} \mathrm{O}_{5}$, as reported in the literature [37]. The $\mathrm{Ta}_{4} \mathrm{f}_{7 / 2}$ and $\mathrm{Ta}_{4} 4 \mathrm{f}_{5 / 2}$ peaks located at $25.0 \mathrm{eV}$ and $26.9 \mathrm{eV}$ are corresponding to $\mathrm{TaO}_{2}$, peaks located at $23.5 \mathrm{eV}$ and $25.4 \mathrm{eV}$, and are categorized to the TaO. The binding energies of the suboxides are close to the values reported by Moo et al [38]; these sub-oxides may exist in the surface layer or may occur due to a reduction of the oxide by the preferential removal of oxygen during Ar etching before XPS scanning [38]. The binding energies of the low energy-doublet $(22.0 \mathrm{eV}$ and $23.9 \mathrm{eV})$ are attributed to metallic tantalum, $\mathrm{Ta}^{0}[36]$. Note that the $\mathrm{Ta} 4 \mathrm{f}$ spectrum of pure $\mathrm{Ta}$ film has a relatively large shoulder at the low energy doublet, which implies the deposited film contains mainly metallic Ta. After corrosion test, the peak width (Fig. 8 (b)) at the low energy doublet decreased significantly and the spectrum shows two primary peaks of $\mathrm{Ta}_{4} 4 \mathrm{f}_{7 / 2}$ and $\mathrm{Ta} 4 \mathrm{f}_{5 / 2}$ peaks located at $26.3 \mathrm{eV}$ and 28.2 $\mathrm{eV}$; this result indicates that the formation of a passive layer of $\mathrm{Ta}_{2} \mathrm{O}_{5}$.

For Ta-N film at $0.25 \mathrm{~N}_{2} / \mathrm{Ar}$ gas ratio $+5 \mathrm{~min}$, the deconvolution of $\mathrm{Ta} 4 \mathrm{f}$ spectrum is shown in Fig. 9 (a), where the $\mathrm{Ta}_{4} \mathrm{f}_{7 / 2}$ and $\mathrm{Ta} 4 \mathrm{f}_{5 / 2}$ peaks positioned at $26.3 \mathrm{eV}$ and $28.2 \mathrm{eV}$ correspond to 
$\mathrm{Ta}_{2} \mathrm{O}_{5}$; there are small peaks corresponding to the $\mathrm{TaO}_{2}$ are also observed $(25.0 \mathrm{eV}$ and $26.9 \mathrm{eV})$. The doublet with the Ta $4 \mathrm{f}_{7 / 2}$ and $\mathrm{Ta} 4 \mathrm{f}_{5 / 2}$ peaks is in close agreement with the values of $25.6 \mathrm{eV}$ and $23.7 \mathrm{eV}$ reported for hexagonal TaN [39]. The TaN peaks are consistent with the result obtained for XRD, where hexagonal TaN phase is observed as the $\mathrm{N}_{2} / \mathrm{Ar}$ gas ratio increased. Representative peaks of metallic $\mathrm{Ta}^{0}$ are also observed in the surface. After corrosion test, the Ta 4f peaks of $\mathrm{Ta}_{2} \mathrm{O}_{5}$ were shifted to lower binding energies by $0.5 \mathrm{eV}$ to $25.8 \mathrm{eV}$ and $27.7 \mathrm{eV}$ for the $4 f_{7 / 2}$ and Ta $4 f_{5 / 2}$ peaks, respectively (Fig. 9 (b)). The peak position of $\mathrm{O} 1 \mathrm{~s}$ shifted to a lower energy by $0.5 \mathrm{eV}$ after corrosion test, as shown in Fig. 9 (c). The high resolution $\mathrm{Ta} 4 \mathrm{p}_{3 / 2} / \mathrm{N} 1 \mathrm{~s}$ spectra in Fig. 9 (d) show similar peak position before and after corrosion tests. The XPS result indicates the formation of $\mathrm{TaON}$ layer on the surface. This result is consistent with the work reported by $\mathrm{Xu}$ et al [12], where the binding energies of the $\mathrm{Ta} 4 \mathrm{f}$ peaks for pure $\mathrm{Ta}_{2} \mathrm{O}_{5}$ coating shift to a lower energy by $0.6 \mathrm{eV}$ for pure TaON coating. The shift in binding energies is caused by covalent bond between $\mathrm{Ta}$ and $\mathrm{N}$ which is greater than between $\mathrm{Ta}$ and $\mathrm{O}$ where the oxygen is more electronegative than nitrogen. The peak intensity and peak width of the $4 f_{5 / 2}$ and $\mathrm{Ta} 4 \mathrm{f}_{7 / 2}$ peaks $(21.4 \mathrm{eV}$ and $23.3 \mathrm{eV})$ at low-energy doublet corresponding to metallic $\mathrm{Ta}^{0}$ decreased after the corrosion test. The TaOx phase on the surface layer acts like a charge barrier layer and protects the substrate from corrosion. As reported by $\mathrm{Xu}$ et al. [12], the TaON coating with a lower charge carrier density, exhibited a higher corrosion resistance than the $\beta-\mathrm{Ta}_{2} \mathrm{O}_{5}$. The charge donor density $\left(\mathrm{N}_{\mathrm{d}}\right)$ is highest for the passive film formed on bare Ti6Al4V alloy $(3.76 \times$ $\left.10^{20} \mathrm{~cm}^{-3}\right)$, followed by the $\beta-\mathrm{Ta}_{2} \mathrm{O}_{5}\left(9.89 \times 10^{18} \mathrm{~cm}^{-3}\right)$ and TaON $\left(7.19 \times 10^{18} \mathrm{~cm}^{-3}\right)$ coatings as calculated from Mott-Schottky plots. This means that the protective oxide film provided by the TaON coating is the most stable and insulating, therefore offers more protection to Ti6A4V alloy than the $\beta-\mathrm{Ta}_{2} \mathrm{O}_{5}$ coating [12]. The Ta-N film at $0.25 \mathrm{~N}_{2} / \mathrm{Ar}$ gas ratio $+5 \mathrm{~min}$ displayed a higher 
corrosion resistance compared to the pure Ta film in this work most likely because of the good passivation effect by the TaON due to its lower charge carrier density. The XPS results confirmed the passive surface oxide and $\mathrm{TaON}$ on the surfaces of pure Ta film and $\mathrm{Ta}-\mathrm{N}$ film at $0.25 \mathrm{~N}_{2} /$ Ar gas ratio $+5 \mathrm{~min}$ after corrosion process, respectively.

The formation of $\mathrm{TaON}$ could be attributed to electrochemical reactivity of $\mathrm{TaN}$ in aqueous media due to its low isoelectric point of 1.0 [40] and presence of negative charge on TaN surface at $\mathrm{pH}$ 7.4. This promotes absorption and interaction with the electronegative species thus formation of oxide or hydrated oxide $\mathrm{TaN}$, i.e. $\mathrm{TaON}$ or $\mathrm{TaON}, \mathrm{xH}_{2} \mathrm{O}$. Similar mechanism has been proposed elsewhere [41] for formation of $\mathrm{TaO}_{\mathrm{x}} \mathrm{N}_{\mathrm{y}}$ upon exposure of $\mathrm{TaN}$ film to SBF. TaON layer would intrinsically exhibit higher inertness compared to TaN and therefore will afford more effective passivation. The $\mathrm{TaON}$ in the surface provided satisfactory resistance to corrosion and leads to a significant improvement of the corrosion resistance in the Ta-N film with a proper thickness of $300 \mathrm{~nm}$ and with mechanical integrity.

\section{Conclusions}

Ta and Ta-N films were deposited by filtered cathodic vacuum arc deposition technique. A hexagonal Ta-N phase in the resultant films was identified with an increase in the $\mathrm{N}_{2} / \mathrm{Ar}$ gas ratio. Ta-N films enhanced the corrosion resistance due to the stability of the passive oxide and oxynitride layers. The low charge carrier density of TaON layer was verified by XPS results and the high electrochemical impedance. A combination of passive chemistry, uniformity and lack of defect in the film made resulted in optimized protective performance by Ta-N film at $0.25 \mathrm{~N}_{2} / \mathrm{Ar}$ 
gas ratio. Further increase in $\mathrm{N}_{2} / \mathrm{Ar}$ gas ratio results in defective film and hence the unstable surface film is susceptible to corrosion attack in simulated biological fluid solution. These results show that Ta-N film prepared by filtered-cathodic-arc deposition technique in an optimized atmosphere and thickness showed improved corrosion resistance that makes Ta-N film a promising candidate for bio-implantable devices.

\section{Acknowledgement}

This work was financially supported by the University Postgraduate Award (UPA), University of Wollongong. The authors acknowledge the use of facilities within the UOW Electron Microscopy Centre. 


\section{References}

[1] H.J. Rack, J.I. Qazi, Titanium alloys for biomedical applications, Mater. Sci. Eng. C. 26 (2006) 1269-1277. doi:10.1016/j.msec.2005.08.032.

[2] N.K. Kuromoto, R.A. Simão, G.A. Soares, Titanium oxide films produced on commercially pure titanium by anodic oxidation with different voltages, Mater. Charact. 58 (2007) 114-121. doi:10.1016/j.matchar.2006.03.020.

[3] J.L. Gilbert, C.A. Buckley, J.J. Jacobs, In vivo corrosion of modular hip prosthesis components in mixed and similar metal combinations. The effect of crevice, stress, motion, and alloy coupling, J. Biomed. Mater. Res. 27 (1993) 1533-1544.

doi:10.1002/jbm.820271210.

[4] N.R. Mody, R.Q. Hwang, S. Venka-taraman, J.E. Angelo, D.P. Norwood, W.W. Gerberich, Adhesion and fracture of tantalum nitride films, Acta Mater. 46 (1998) 585597. doi:10.1016/S1359-6454(97)00243-7.

[5] X. Liu, P.K. Chu, C. Ding, Surface modification of titanium, titanium alloys, and related materials for biomedical applications, Mater. Sci. Eng. R Reports. 47 (2004) 49-121. doi:10.1016/j.mser.2004.11.001.

[6] T. Lu, J. Wen, S. Qian, H. Cao, C. Ning, X. Pan, X. Jiang, X. Liu, P.K. Chu, Enhanced osteointegration on tantalum-implanted polyetheretherketone surface with bone-like elastic modulus, Biomaterials. 51 (2015) 173-183. doi:10.1016/j.biomaterials.2015.02.018.

[7] Y. Zhu, Y. Gu, S. Qiao, L. Zhou, J. Shi, H. Lai, Bacterial and mammalian cells adhesion to tantalum-decorated micro-/nano-structured titanium, J. Biomed. Mater. Res. Part A. 105 (2016) 871-878. doi:10.1002/jbm.a.35953.

[8] F. Meng, Z. Li, X. Liu, Synthesis of tantalum thin films on titanium by plasma immersion ion implantation and deposition, Surf. Coatings Technol. 229 (2013) 205-209. doi:10.1016/J.SURFCOAT.2012.04.044.

[9] Y. Zhang, Y. Zheng, Y. Li, L. Wang, Y. Bai, Q. Zhao, X. Xiong, Y. Cheng, Z. Tang, Y. Deng, S. Wei, Tantalum nitride-decorated titanium with enhanced resistance to microbiologically induced corrosion and mechanical property for dental application, PLoS One. 10 (2015) 1-22. doi:10.1371/journal.pone.0130774.

[10] Y.X. Leng, H. Sun, P. Yang, J.Y. Chen, J. Wang, G.J. Wan, N. Huang, X.B. Tian, L.P. Wang, P.K. Chu, Biomedical properties of tantalum nitride films synthesized by reactive magnetron sputtering, Thin Solid Films. 398-399 (2001) 471-475. doi:10.1016/S00406090(01)01448-1.

[11] J. Xu, W. Hu, S. Xu, P. Munroe, Z.-H. Xie, Electrochemical properties of a novel $\beta-\mathrm{Ta}_{2} \mathrm{O}_{5}$ nanoceramic coating exposed to simulated body solutions, ACS Biomater. Sci. Eng. 2 (2016) 73-89. doi:10.1021/acsbiomaterials.5b00384.

[12] J. Xu, W. Hu, Z.-H. Xie, P. Munroe, Reactive-sputter-deposited $\beta-\mathrm{Ta}_{2} \mathrm{O}_{5}$ and $\mathrm{TaON}$ 
nanoceramic coatings on $\mathrm{Ti}-6 \mathrm{Al}-4 \mathrm{~V}$ alloy against wear and corrosion damage, Surf. Coatings Technol. 296 (2016) 171-184. doi:10.1016/j.surfcoat.2016.04.004.

[13] H. Ha, H. Jang, H. Kwon, S. Kim, Effects of nitrogen on the passivity of Fe-20Cr alloy, Corros. Sci. 51 (2009) 48-53. doi:10.1016/j.corsci.2008.10.017.

[14] R.C. Newman, M.A.A. Ajjawi, A micro-electrode study of the nitrate effect on pitting of stainless steels, Corros. Sci. 26 (1986) 1057-1063. doi:10.1016/0010-938X(86)90133-2.

[15] A.C. Hee, S.S. Jamali, A. Bendavid, P.J. Martin, C. Kong, Y. Zhao, Corrosion behaviour and adhesion properties of sputtered tantalum coating on Ti6Al4V substrate, Surf. Coatings Technol. 307 (2016) 666-675. doi:10.1016/j.surfcoat.2016.09.061.

[16] A.C. Hee, Y. Zhao, S.S. Jamali, P.J. Martin, A. Bendavid, H. Peng, X. Cheng, Corrosion behaviour and microstructure of tantalum film on Ti6Al4V substrate by filtered cathodic vacuum arc deposition, Thin Solid Films. 636 (2017) 54-62. doi:10.1016/j.tsf.2017.05.030.

[17] A.C. Hee, P.J. Martin, A. Bendavid, S.S. Jamali, Y. Zhao, Tribo-corrosion performance of filtered-arc-deposited tantalum coatings on Ti-13Nb-13Zr alloy for bio-implants applications, Wear. 400-401 (2018) 31-42. doi:10.1016/J.WEAR.2017.12.017.

[18] L. Mendizabal, R. Bayón, E. G-Berasategui, J. Barriga, J.J. Gonzalez, Effect of $\mathrm{N}_{2}$ flow rate on the microstructure and electrochemical behavior of TaNx films deposited by modulated pulsed power magnetron sputtering, Thin Solid Films. 610 (2016) 1-9. doi:10.1016/j.tsf.2016.04.043.

[19] L. Li, E. Niu, G. Lv, X. Zhang, H. Chen, S. Fan, C. Liu, S.-Z. Yang, Synthesis and electrochemical characteristics of Ta-N thin films fabricated by cathodic arc deposition, Appl. Surf. Sci. 253 (2007) 6811-6816. doi:10.1016/j.apsusc.2007.01.128.

[20] M. Prabhu, R. Suriyaprabha, V. Rajendran, P. Kulandaivelu, S. Valiyaveettil, In vivo cytotoxicity of $\mathrm{MgO}$-doped nanobioactive glass particles and their anticorrosive coating on Ti-6Al-4V and SS304 implants for high load-bearing applications, RSC Adv. 4 (2014) 43630-43640. doi:10.1039/C4RA04892J.

[21] X. Li, P. Gao, P. Wan, Y. Pei, L. Shi, B. Fan, C. Shen, X. Xiao, K. Yang, Z. Guo, Novel Bio-functional Magnesium Coating on Porous Ti6A14V Orthopaedic Implants: In vitro and In vivo Study, Sci. Rep. 7 (2017) 40755. doi:10.1038/srep40755.

[22] N. Lin, Q. Liu, J. Zou, D. Li, S. Yuan, Z. Wang, B. Tang, Surface damage mitigation of Ti6A14V alloy via thermal oxidation for oil and gas exploitation application: characterization of the microstructure and evaluation of the surface performance, RSC Adv. 7 (2017) 13517-13535. doi:10.1039/C6RA28421C.

[23] S.K. Kim, B.C. Cha, Deposition of tantalum nitride thin films by D.C. magnetron sputtering, Thin Solid Films. 475 (2005) 202-207. doi:10.1016/j.tsf.2004.08.059.

[24] X. Sun, E. Kolawa, J.S. Chen, J.S. Reid, M.A. Nicolet, Properties of reactively sputterdeposited TaN thin films, Thin Solid Films. 236 (1993) 347-351. doi:10.1016/0040- 
6090(93)90694-K.

[25] C. Stampfl, A.J. Freeman, Stable and metastable structures of the multiphase tantalum nitride system, Phys. Rev. B. 71 (2005) 024111. doi:10.1103/PhysRevB.71.024111.

[26] L. Ponsonnet, K. Reybier, N. Jaffrezic, V. Comte, C. Lagneau, M. Lissac, C. Martelet, Relationship between surface properties (roughness, wettability) of titanium and titanium alloys and cell behaviour, Mater. Sci. Eng. C. 23 (2003) 551-560. doi:10.1016/S09284931(03)00033-X.

[27] G. Altankov, F. Grinnell, T. Groth, Studies on the biocompatibility of materials: Fibroblast reorganization of substratum-bound fibronectin on surfaces varying in wettability, J. Biomed. Mater. Res. 30 (1996) 385-391. doi:10.1002/(SICI)10974636(199603)30:3<385::AID-JBM13>3.0.CO;2-J.

[28] Qing Wang, A. Jacques-E. Moser, M. Grätzel, Electrochemical impedance spectroscopic analysis of dye-sensitized solar cells, J. Phys. Chem. B. 109 (2005) 14945-14953. doi:10.1021/JP052768H.

[29] M. Alishahi, F. Mahboubi, S.M. Mousavi Khoie, M. Aparicio, E. Lopez-Elvira, J. Méndez, R. Gago, Structural properties and corrosion resistance of tantalum nitride coatings produced by reactive DC magnetron sputtering, RSC Adv. 6 (2016) 89061-89072. doi:10.1039/C6RA17869C.

[30] U. Rammelt, G. Reinhard, On the applicability of a constant phase element (CPE) to the estimation of roughness of solid metal electrodes, Electrochim. Acta. 35 (1990) 10451049. doi:10.1016/0013-4686(90)90040-7.

[31] T. Wei, F. Yan, J. Tian, Characterization and wear- and corrosion-resistance of microarc oxidation ceramic coatings on aluminum alloy, J. Alloys Compd. 389 (2005) 169-176. doi:10.1016/j.jallcom.2004.05.084.

[32] T. Miyazaki, H.-M. Kim, T. Kokubo, C. Ohtsuki, H. Kato, T. Nakamura, Mechanism of bonelike apatite formation on bioactive tantalum metal in a simulated body fluid, Biomaterials. 23 (2002) 827-832. doi:10.1016/S0142-9612(01)00188-0.

[33] T. Kokubo, Apatite formation on surfaces of ceramics, metals and polymers in body environment, Acta Mater. 46 (1998) 2519-2527. doi:10.1016/S1359-6454(98)80036-0.

[34] C. Valero Vidal, A. Igual Muñoz, Electrochemical characterisation of biomedical alloys for surgical implants in simulated body fluids, Corros. Sci. 50 (2008) 1954-1961. doi:10.1016/j.corsci.2008.04.002.

[35] M. Khanuja, H. Sharma, B.R. Mehta, S.M. Shivaprasad, XPS depth-profile of the suboxide distribution at the native oxide/Ta interface, J. Electron Spectros. Relat. Phenomena. 169 (2009) 41-45. doi:10.1016/j.elspec.2008.10.004.

[36] O. Kerrec, D. Devilliers, H. Groult, P. Marcus, Study of dry and electrogenerated $\mathrm{Ta}_{2} \mathrm{O}_{5}$ and $\mathrm{Ta} / \mathrm{Ta}_{2} \mathrm{O}_{5} / \mathrm{Pt}$ structures by XPS, Mater. Sci. Eng. B. 55 (1998) 134-142.

doi:10.1016/S0921-5107(98)00177-9. 
[37] M. Hara, E. Chiba, A. Ishikawa, T. Takata, J.N. Kondo, Kazunari Domen, $\mathrm{Ta}_{3} \mathrm{~N}_{5}$ and TaON thin films on Ta foil: surface composition and stability, J. Phys. Chem. B. (2003) 3115-3123. doi:10.1021/JP036189T.

[38] J.G.S. Moo, Z. Awaludin, T. Okajima, T. Ohsaka, An XPS depth-profile study on electrochemically deposited TaOx, J. Solid State Electrochem. 17 (2013) 3115-3123. doi:10.1007/s10008-013-2216-y.

[39] A. Arranz, C. Palacio, Composition of tantalum nitride thin films grown by low-energy nitrogen implantation: a factor analysis study of the Ta $4 \mathrm{f}$ XPS core level, Appl. Phys. A. 81 (2005) 1405-1410. doi:10.1007/s00339-004-3182-0.

[40] W.-J. Chun, A. Ishikawa, H. Fujisawa, T. Takata, J.N. Kondo, M. Hara, M. Kawai, Y. Matsumoto, K. Domen, Conduction and valence band positions of $\mathrm{Ta}_{2} \mathrm{O}_{5}, \mathrm{TaON}$, and $\mathrm{Ta}_{3} \mathrm{~N}_{5}$ by UPS and electrochemical methods, J. Phys. Chem. B. 107 (2003) 1798-1803. doi:10.1021/jp027593f.

[41] J. Xu, L. Liu, P. Munroe, Z.-H. Xie, Promoting bone-like apatite formation on titanium alloys through nanocrystalline tantalum nitride coatings, J. Mater. Chem. B. 3 (2015) 4082-4094. doi:10.1039/C5TB00236B. 


\section{Figure Captions}

Fig. 1 X-ray diffraction patterns of the uncoated Ti6Al4V and Ta-N films at various $\mathrm{N}_{2} / \mathrm{Ar}$ gas ratios.

Fig. 2 AFM deflection images of the Ta-N films at $\mathrm{N}_{2} /$ Ar gas ratio of (a) 0 (b) 0.25 (c) 0.50 (d) 0.75 , all with a Z- full range of $30 \mathrm{mV}$.

Fig. 3 Nyquist and Bode impedance spectra of Ta-N films at different $\mathrm{N}_{2} /$ Ar gas ratios.

Fig. 4 Electronic equivalent circuits (EEC) used in the fitting procedure of the EIS experimental data.

Fig. 5 SEM images of Ta and Ta-N films after electrochemical measurement (a) $0 \mathrm{~N}_{2} / \mathrm{Ar}$ gas ratio+5min; (b) $0.25 \mathrm{~N}_{2} / \mathrm{Ar}$ gas ratio+5min; (c) $0.50 \mathrm{~N}_{2} / \mathrm{Ar}$ gas ratio $+5 \mathrm{~min}$; (d) $0.75 \mathrm{~N}_{2} / \mathrm{Ar}$ gas ratio+5min; (e) $0 \mathrm{~N}_{2} / \mathrm{Ar}$ gas ratio $+30 \mathrm{~min}$; (f) $0.50 \mathrm{~N}_{2} / \mathrm{Ar}$ gas ratio $+30 \mathrm{~min}$.

Fig. 6 Energy dispersive $\mathrm{X}$-ray spectrum of the sample $0 \mathrm{~N}_{2} / \mathrm{Ar}$ gas ratio $+5 \mathrm{~min}$. Data is associated with the area shown in Fig. 5 (a).

Fig. $7 \mathrm{SEM}$ images of $0.50 \mathrm{~N}_{2} / \mathrm{Ar}$ gas ratio $+5 \mathrm{~min}$ Ta-N film after electrochemical measurement at magnification of $(\mathrm{a}) \times 50$ (b) $\times 1000$.

Fig. 8 X-ray spectroscopy spectra of the (a) pure Ta film before corrosion test; (b) pure Ta film after corrosion test.

Fig. 9 X-ray spectroscopy spectra of the Ta-N film at $0.25 \mathrm{~N}_{2} / \mathrm{Ar}$ gas ratio $+5 \mathrm{~min}$ (a) Ta $4 \mathrm{f}$ spectrum before corrosion test; (b) Ta 4f spectrum after corrosion test; (c) O 1s spectra; (d) Ta $4 \mathrm{P} / \mathrm{N} 1$ s spectra. 


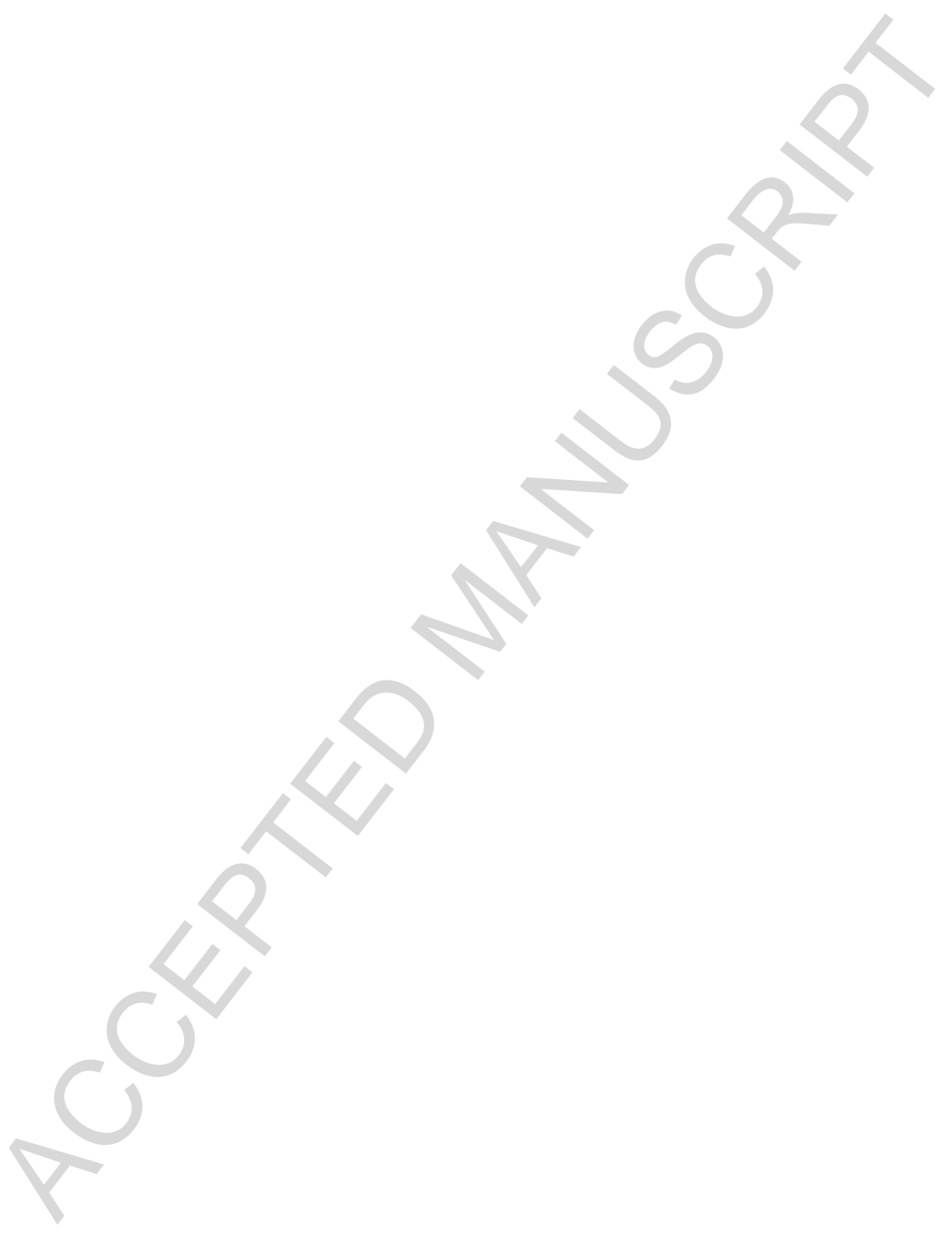




\section{Table 1.}

Deposition parameters of the Ta and Ta-N films.

\begin{tabular}{|c|c|c|c|c|}
\hline \multirow[t]{2}{*}{$\mathrm{N}_{2} / \mathrm{Ar}$ gas ratio } & \multicolumn{2}{|c|}{ Mass flow rate } & \multirow{2}{*}{$\begin{array}{l}\text { Average ion } \\
\text { beam current (A) }\end{array}$} & Deposition \\
\hline & $\mathrm{N}_{2}(\mathrm{sccm} *)$ & $\operatorname{Ar}\left(\mathrm{sccm}^{*}\right)$ & & time (min) \\
\hline 0 & 0 & 20 & 0.04 & 5 \\
\hline 0.25 & 5 & 15 & 0.06 & \\
\hline 0.50 & 10 & 10 & 0.08 & 5 \\
\hline 0.75 & 15 & 5 & 0.10 & 5 \\
\hline 0 & 0 & 20 & 0.04 & 30 \\
\hline 0.50 & 10 & 10 & 0.08 & 30 \\
\hline
\end{tabular}

*sccm (standard cubic centimetre per minute)

\section{Table 2.}

Contact angle values of each sample. Note that $\mathrm{N}_{2} / \mathrm{Ar}$ gas ratio of 0 indicates that the Ta coating was deposited in pure argon atmosphere.

\begin{tabular}{lcllll}
\hline Sample & Ti6Al4V & \multicolumn{4}{c}{$\mathrm{N}_{2}$ /Ar gas ratio } \\
& substrate & 0 & 0.25 & 0.50 & 0.75 \\
& & & & & \\
\hline Water contact angle $\left(^{\circ}\right)$ & $70.3 \pm 2$ & $89.1 \pm 2$ & $87.1 \pm 1$ & $87.4 \pm 2$ & $86.5 \pm 1$ \\
Fetal bovine serum contact angle $\left(^{\circ}\right)$ & $77.2 \pm 1$ & $73.7 \pm 1$ & $88.1 \pm 3$ & $85.4 \pm 2$ & $81.7 \pm 1$
\end{tabular}

Data are shown as mean \pm standard deviation. 


\section{Table 3.}

Electrical components calculated by fitting an equivalent electrical circuit on the EIS data.

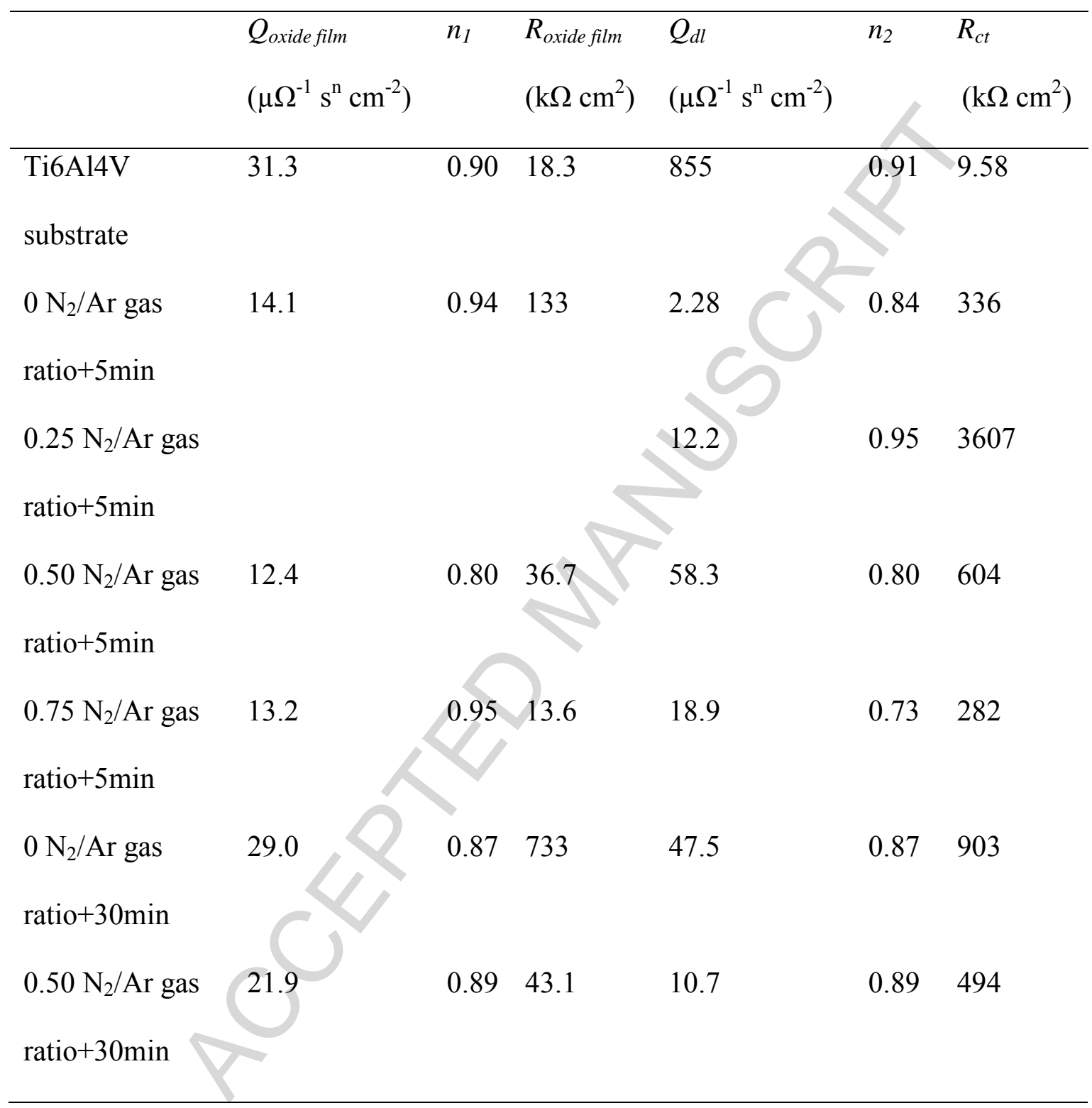




\section{Table 4.}

XPS result for

\begin{tabular}{llllll}
\hline Sample & $\begin{array}{l}\mathrm{Ta} \\
+\mathrm{TaOx}\end{array}$ & $\begin{array}{l}\mathrm{N} \\
(\text { at. } \%)\end{array}$ & $\begin{array}{l}\mathrm{O} \\
(\text { at. } \%)\end{array}$ & $\begin{array}{l}\mathrm{C} \\
(\text { at. \%) }\end{array}$ & $\begin{array}{l}\text { (at. \%) } \\
\text { (at. \%) }\end{array}$ \\
\hline Ti-6Al-4V substrate & 10.5 & - & 49.6 & 37.7 & 2.3 \\
$0 \mathrm{~N}_{2} /$ Ar gas ratio & 26.1 & 3.9 & 53.5 & 16.5 & \\
$0.25 \mathrm{~N}_{2} /$ Ar gas ratio & 18.7 & 7.6 & 42.9 & 30.8 & \\
$0.50 \mathrm{~N}_{2} /$ Ar gas ratio & 17.8 & 8.4 & 40.3 & 33.4 & \\
$0.75 \mathrm{~N}_{2} /$ Ar gas ratio & 21.0 & 6.5 & 44.8 & 27.8 \\
\hline
\end{tabular}




\section{Highlights}

- Incorporation of nitrogen improves the corrosion resistance of Ta coated Ti6Al4V.

- XPS results confirm the formation of a TaON after corrosion of the TaN film surface.

- The improved corrosion resistance was attributed mainly to the formation of TaON. 


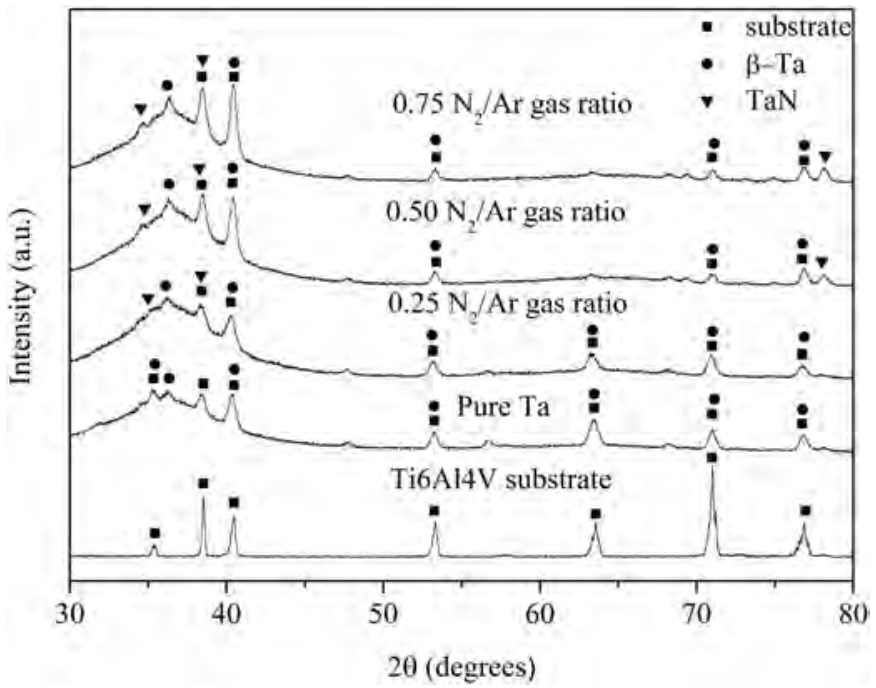

Figure 1 
(a)

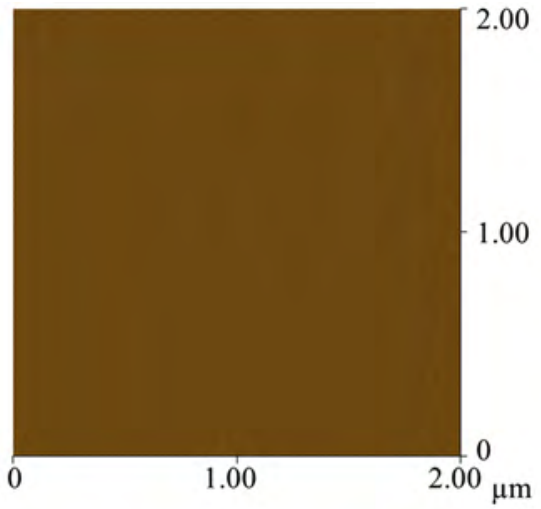

(c)

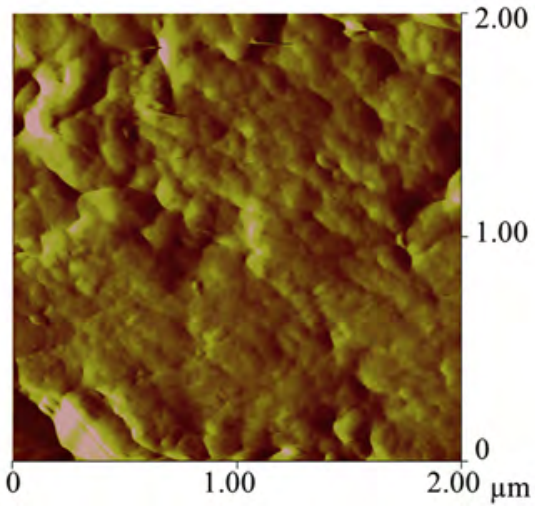

(b)

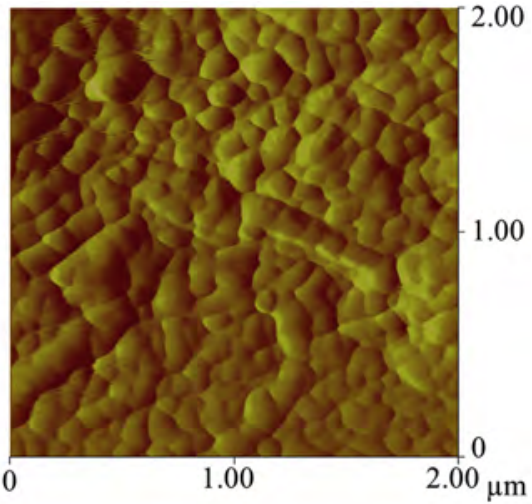

(d)

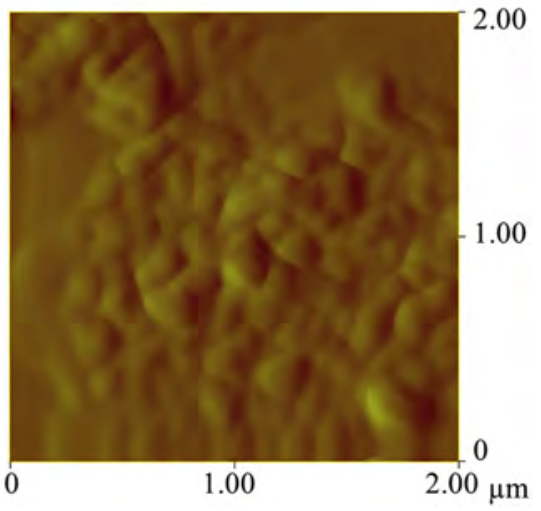

Figure 2 

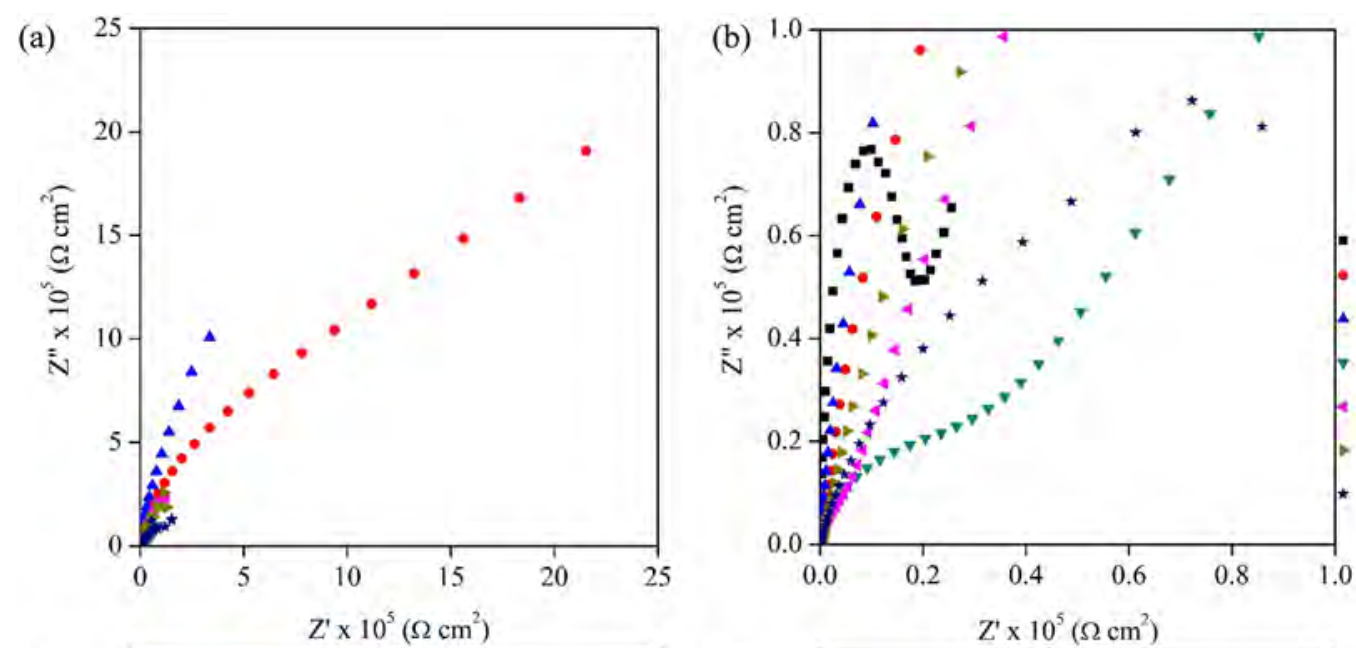

Ti6Al4V substrate

$0 \mathrm{~N}_{2} / \mathrm{Ar}$ gas ratio $+5 \mathrm{~min}$

$0.25 \mathrm{~N}_{2} / \mathrm{Ar}$ gas ratio $+5 \mathrm{~min}$

$0.50 \mathrm{~N}_{2} / \mathrm{Ar}$ gas ratio $+5 \mathrm{~min}$

$0.75 \mathrm{~N}_{2} /$ Ar gas ratio $+5 \mathrm{~min}$

$0 \mathrm{~N}_{2} / \mathrm{Ar}$ gas ratio $+30 \mathrm{~min}$

$0.50 \mathrm{~N}_{2} / \mathrm{Ar}$ gas ratio $+30 \mathrm{~min}$
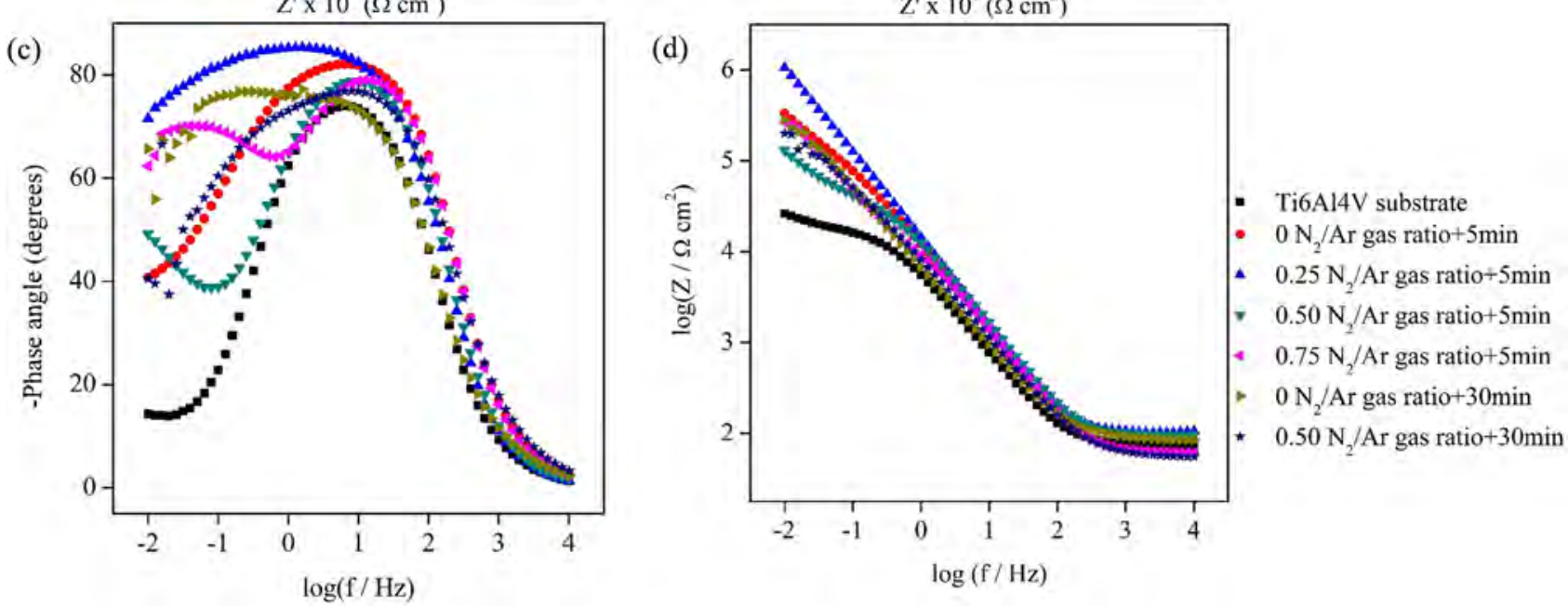

Figure 3 
(a)

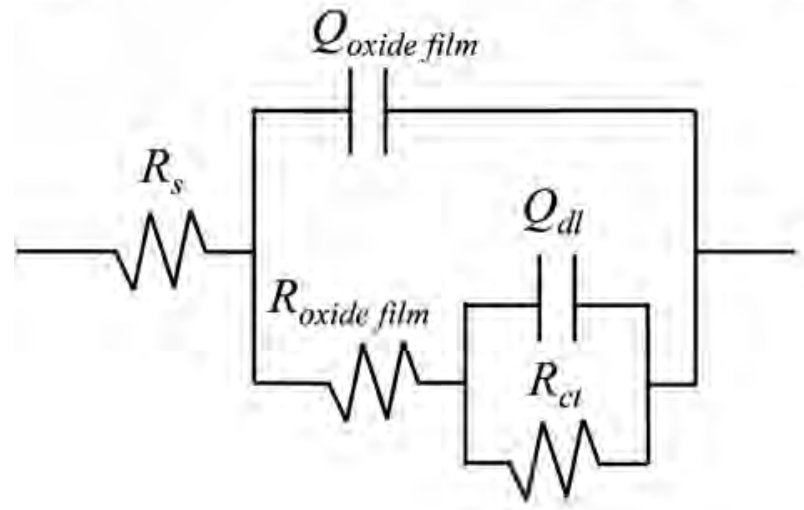

(b)

$\mathrm{R}_{\mathrm{s}}(\mathrm{QR})$

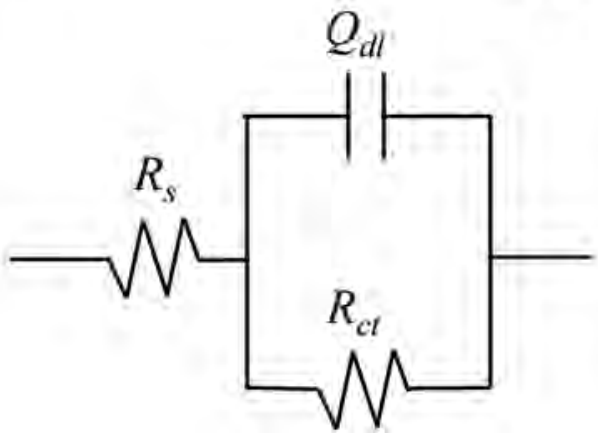

Figure 4 


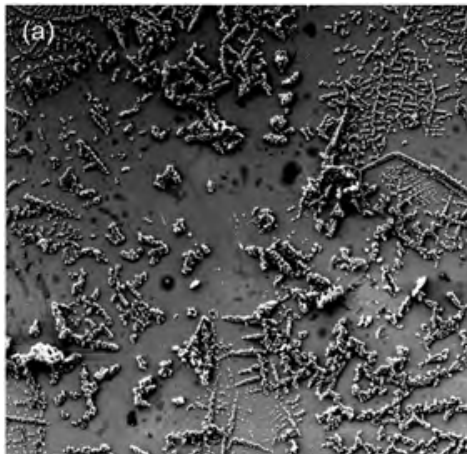

30 .

(c)

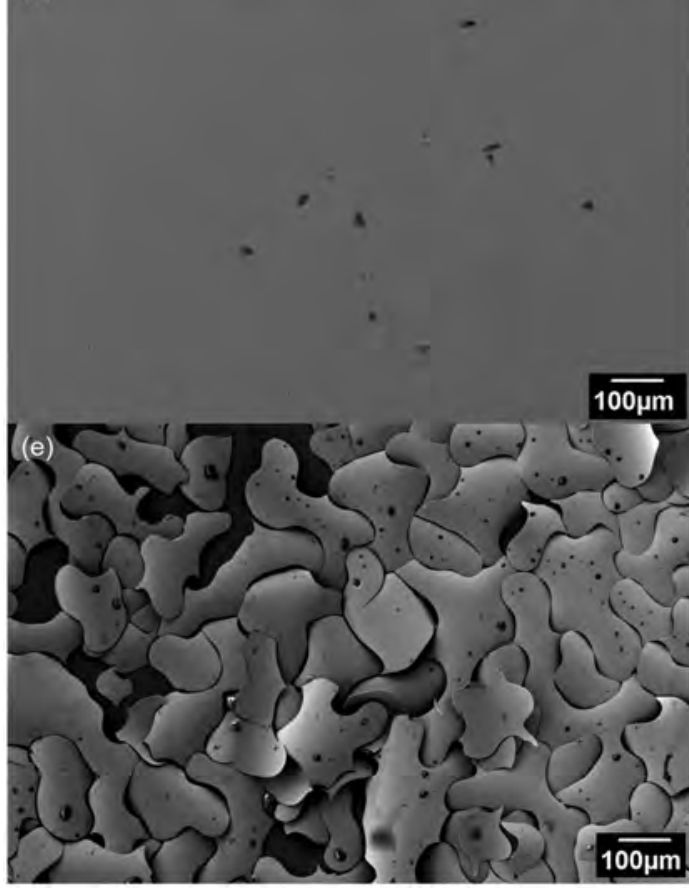
- mos $=4$ (b)

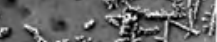
o. $+30=$ ?

(4) 8 - is 32 $2 x \frac{8}{39}=0$

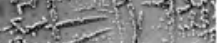

(3)

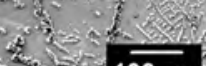

(d)

$\widehat{100 \mu \mathrm{m}}$

(f)

Figure 5 


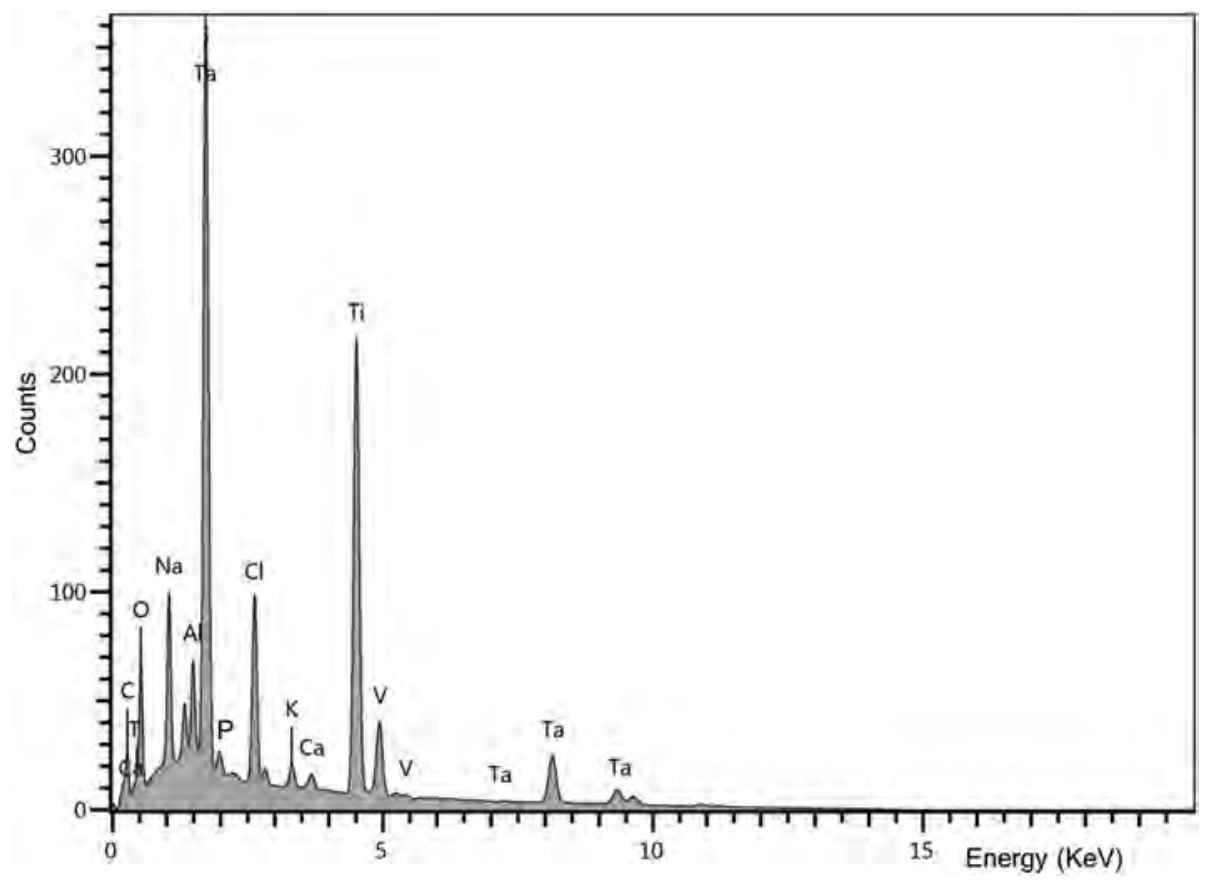

Figure 6 


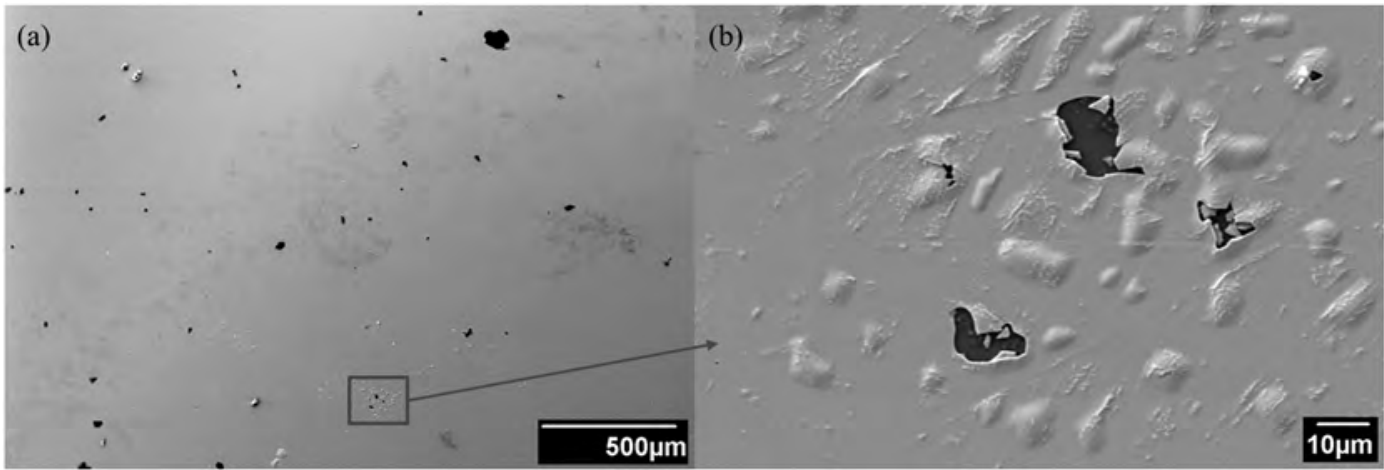

Figure 7 

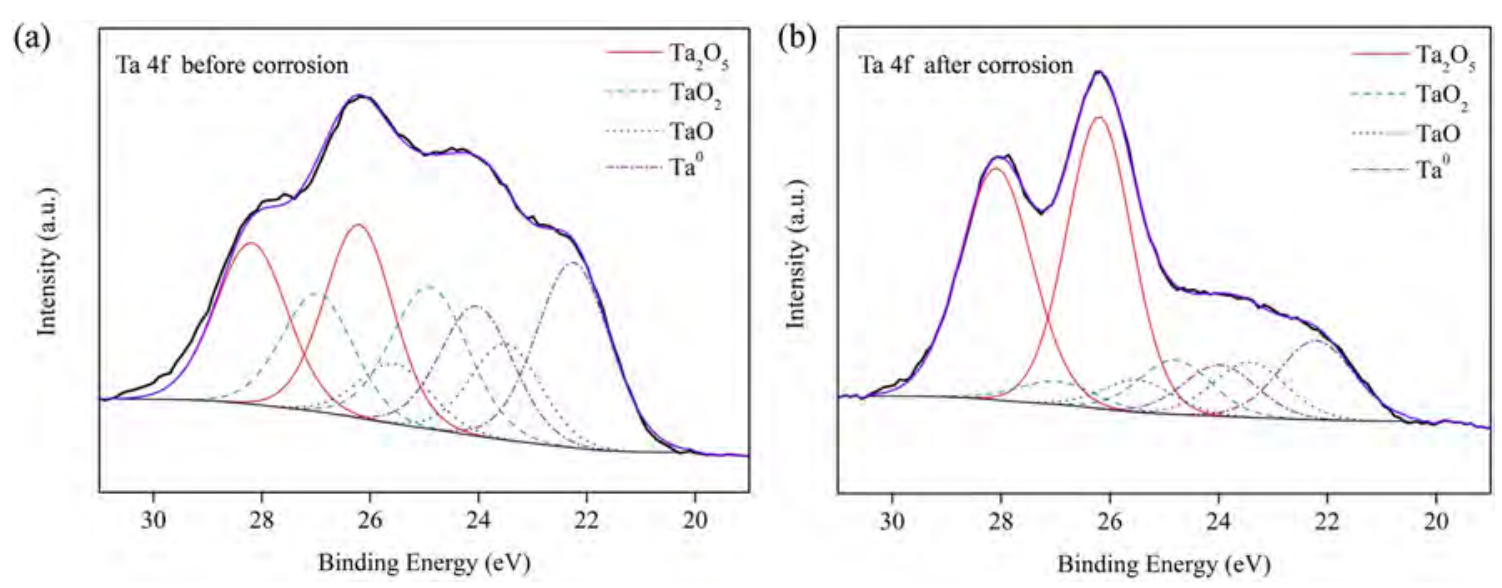

Figure 8 
(a)

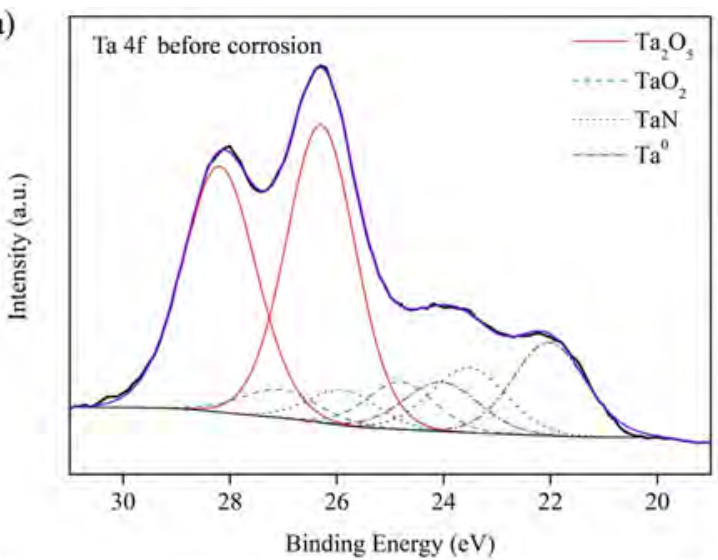

(c)

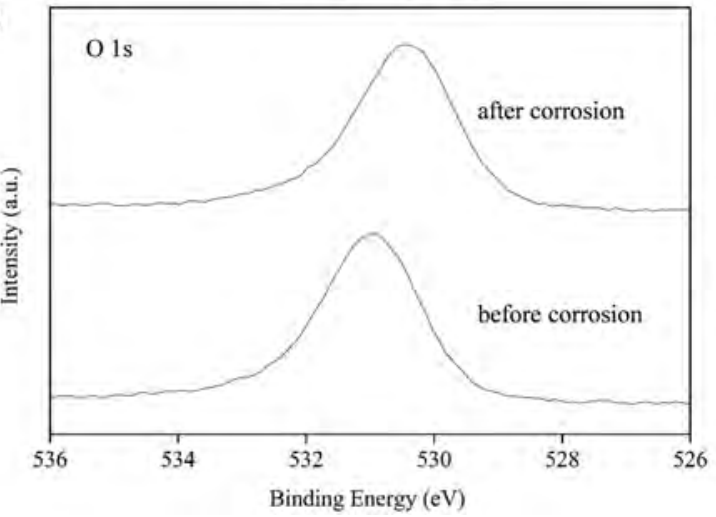

(b)

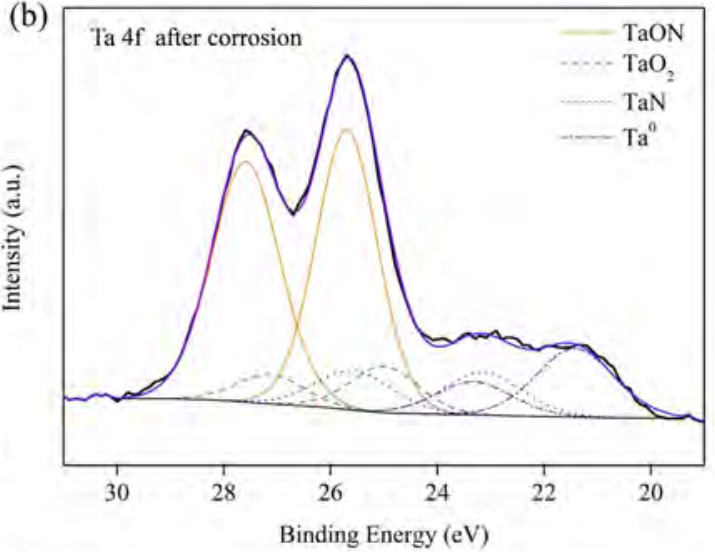

(d)

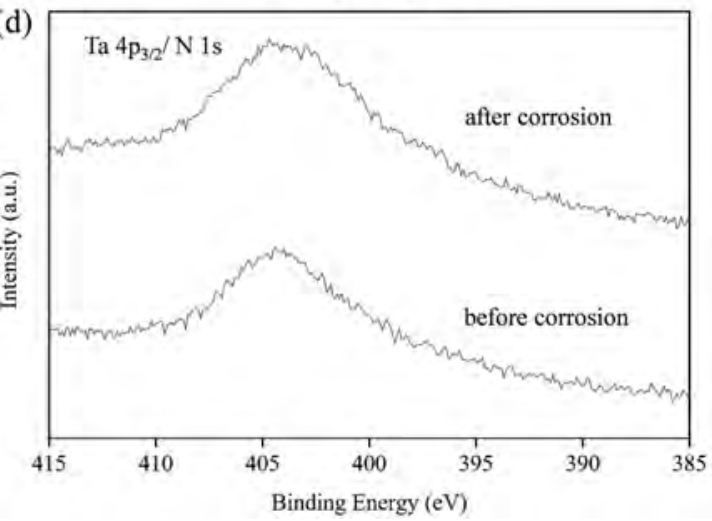

Figure 9 